\begin{tabular}{|c|c|c|}
\hline $\begin{array}{l}\text { ISSN 2525-4812 (versão online) } \\
\text { ISSN 2238-7641 (versão impressa) } \\
\text { http://www.revistaterceiramargem.com/ } \\
\text { index.php/terceiramargem/index }\end{array}$ & $\begin{array}{c}\text { Recebido em: 30/6/2019 } \\
\text { Aprovado em: 14/4/2020 } \\
\text { Período de publicação: jan./jun., } 2020\end{array}$ & $\begin{array}{c}\text { Revista Terceira } \\
\text { Margem Amazônia } \\
(\text { v. } 6 \cdot \text { n. } 14 \cdot \text { Jan./Jun. } 2020)\end{array}$ \\
\hline
\end{tabular}

Como citar o artigo:

OLIVEIRA, T.C.S. de. Em busca de uma nova tecnologia de gestão: a experiência das incubadoras tecnológicas de economia solidária. Revista Terceira Margem Amazônia, v. 6, n. 14, p. 43-61, 2020. DOI: http://dx.doi.org/10.36882/2525-4812. 2020v6i14p43-61

\title{
EM BUSCA DE UMA NOVA TECNOLOGIA DE GESTÃO: A EXPERIÊNCIA DAS INCUBADORAS TECNOLÓGICAS DE ECONOMIA SOLIDÁRIA ${ }^{1}$
}

Thaís Cristina Souza de Oliveira ${ }^{2}$

\begin{abstract}
Resumo: A fim de promover trocas econômicas mais justas e imbricadas com a transformação social, as incubadoras tecnológicas de economia solidária (Ites) têm atuado com o objetivo de desenvolver conhecimentos e tecnologias que sejam úteis à viabilidade e sustentabilidade dos empreendimentos econômicos solidários (EES). Com o objetivo de verificar se novos conhecimentos estão sendo construídos para dar conta da gestão desses empreendimentos selecionaram-se três incubadoras, que passaram por uma entrevista semiestruturada e por uma análise documental com foco na metodologia de incubação. As análises das experiências das Ites demonstraram que já existem processos educativos em curso que conseguem propor novas formas democráticas de gestão, reconhecendo as diversas racionalidades e saberes envolvidos na criação e gestão de um EES.
\end{abstract}

Palavras-chave: incubadoras tecnológicas de economia solidária (Ites), gestão de empreendimentos econômicos solidários, modos de gestão, assessoria.

\section{SEARCH OF A NEW MANAGEMENT TECHNOLOGY: THE EXPERIENCE OF SOLIDARITY ECONOMY TECHNOLOGY INCUBATORS}

\begin{abstract}
In order to promote fairer economic exchanges committed to social transformation, the Solidarity Economy Technological Incubators have been working with the objective of developing knowledge and technologies that are useful for the viability and sustainability of Solidarity Economic Enterprises (EES). So as to identify what new knowledge is being created to account for the management of these enterprises, three incubators were selected, which underwent a semistructured interview and a documentary analysis focusing on the incubation methodology. The analyzes of the experiences of the ITES have demonstrated that there are already educational processes happening that can propose new democratic forms of management, recognizing the diverse rationalities and knowledge involved in the creation and management of an ESS.
\end{abstract}

Key words: management of solidarity economic enterprises, assessorship, solidarity economy technological incubators, new management modes.

\footnotetext{
${ }^{1}$ Este artigo é parte da Dissertação de Mestrado apresentada ao Programa de Pós-Graduação Profissional em Tecnologia para o Desenvolvimento Social, Núcleo Interdisciplinar para o Desenvolvimento Social, Universidade Federal do Rio de Janeiro, em agosto de 2018, sob orientação do professor Flávio Chedid Henriques.

${ }^{2}$ Administradora, M.Sc. em Tecnologia para o Desenvolvimento Social, orientadora educacional do Instituto E-Dinheiro Brasil. E-mail: thaiscs.oliveira@yahoo.com.br
} 


\section{Introdução}

Em busca de uma abordagem ampliada de economia, o fenômeno da economia solidária pode ser entendido como um conjunto de experiências econômicas e sociais alternativas de inserção social, que englobam importantes casos de resistência ao desemprego e de práticas organizacionais e territoriais que inovam ao construírem novas formas de sociabilidade, com espaços abertos para a constituição de uma identidade coletiva dos trabalhadores baseada em relações de solidariedade, para a recuperação de sua dignidade e a religação entre o social e o econômico (HENRIQUES, 2015; LEITE, 2009).

Dentre esses casos destacam-se os empreendimentos econômicos solidários, que, de acordo com Silva Junior (2006), possuem uma série de especificidades ao buscar conciliar a tensão entre a lógica mercantil e solidária. De um lado, os EES precisam se inserir no mercado para realizar atividades comerciais e precisam lidar com as exigências desse processo, onde há uma preponderância da racionalidade utilitária; por outro lado, há uma intenção interna de promover a cooperação, as relações de proximidade com a comunidade e de pensar os interesses sociais e coletivos acima dos interesses individuais, destacando assim uma racionalidade substantiva.

Nesse sentido, a sustentabilidade desses empreendimentos vai depender de uma convergência de fatores, dentre eles a conquista de tecnologias adequadas a sua realidade e a exigência de conhecimento por parte dos integrantes dos grupos e das condições necessárias para assumirem a condução de seu empreendimento. Assim, Rutkowski (2008) salienta que há uma necessidade de um novo arcabouço teórico-metodológico a ser desenvolvido, uma vez que esses empreendimentos adotam formas alternativas de conhecimento, baseadas, muitas vezes, em visões diferenciadas do mundo, que devem ser respeitadas e até mesmo reconhecidas como inovações.

Considerando que hoje são poucos os conhecimentos em administração capazes de dar conta das especificidades dos empreendimentos econômicos solidários (EES) (CALBINO; PAULA, 2012; RUTKOWSKI, 2008), o presente artigo pretendeu analisar as experiências das incubadoras tecnológicas de economia solidária para verificar que conhecimentos e tecnologias em gestão estão sendo produzidos para dar conta da realidade e especificidade dos EES.

Criadas inicialmente com o objetivo de gerar trabalho e renda nos anos 1990, diante da crise econômica que assolava o País, hoje, as Ites, além de apoiar os processos de auto-organização de grupos socialmente excluídos, por meio da extensão universitária, produz com a sua prática novos insumos de pesquisa que vão auxiliar a construção de novos conhecimentos, novos processos de aprendizagem e a mobilização e integração de diversas áreas do saber (OLIVEIRA et al., 2018).

\section{Referencial Teórico}

\section{Economia Solidária e as Incubadoras}

Conjugar economia e solidariedade, a princípio, parece uma contradição. Tradicionalmente, a economia de mercado e o mercado são entendidos como sistemas que não podem ser solidários, pois se o fossem deixariam de ser mercado, uma vez que estaria na estrutura do mercado ser 
competitivo e individualista. Em uma acepção formal de economia, entende-se que o econômico é aquele que faz mais com os mesmos recursos. Trata-se de encontrar a melhor solução possível, que é a que produz mais benefícios, mais utilidade e mais satisfação (CORAGGIO, 2012).

Em contraponto a essa proposição, alguns autores, como Coraggio (2012) e França Filho (2007), buscam reconhecer uma noção de economia substantiva. Para Coraggio (2012), numa economia substantiva, o dever das atividades seria o sustento dos cidadãos e a reprodução da vida de todos, e não somente daqueles que tem êxito.

Essa forma de economia substantiva encontra respaldo nos termos da economia solidária, que propõe criar relações econômicas mais igualitárias e justas, onde possa haver um bem-viver de todos. Uma economia que reconheça as diversas relações de troca, sem que haja uma subordinação de uma pela outra; e uma economia que reconheça o outro como alguém que tem direito à reprodução da vida e ao mesmo tempo lhe assegure esse direito (CORAGGIO, 2012).

Reconhece-se hoje que a economia solidária seria um conjunto de experiências alternativas de inserção social e econômica. Embora ainda não tenham as condições necessárias para gerar uma profunda transformação social, elas apontam experiências importantes de resistência ao desemprego, de práticas organizacionais inovadoras em relação ao capital e novas formas de sociabilidade, com espaços abertos para a constituição de uma identidade coletiva dos trabalhadores, para a recuperação de sua dignidade e a religação entre o social e o econômico (HENRIQUES, 2015; LEITE, 2009).

Dentre os autores que caracterizam a economia solidária como fenômeno histórico, Singer (2002) é quem atrela o surgimento da economia solidária ao movimento cooperativista. Para o autor, a economia solidária nasce pouco depois do capitalismo industrial, como reação dos trabalhadores e dos artesões ao espantoso empobrecimento provocado pela difusão das máquinas e da organização fabril da produção.

No Brasil, a economia solidária surge ao longo dos anos de 1990 e tem sua atuação bastante atrelada às instituições que surgiram no Brasil para assessorar os empreendimentos coletivos e que utilizavam o conceito de cooperativas populares, como o Fórum de Cooperativismo Popular do Rio de Janeiro (FCP) e a Incubadora Tecnológica de Cooperativas Populares (ITCP), surgida no Instituto Alberto Luiz Coimbra de Pós-Graduação e Pesquisa em Engenharia da Universidade Federal do Rio de Janeiro (COPPE/UFRJ) (HENRIQUES, 2013).

Em meio à crise econômica dos anos 1990, as incubadoras surgiram com o propósito de gerar recursos e conhecimentos que tivessem impacto a longo prazo na vida das pessoas, com a geração de trabalho e renda. Apesar de ter inspirações nos modelos de incubadoras tecnológicas, voltadas para empresas, no Brasil as incubadoras foram construídas com base nos princípios e nas práticas da extensão universitária e da educação popular. Atualmente, as ITCPs têm ganhado destaque no ambiente universitário, com ações que buscam unir a pesquisa, o ensino e a extensão num propósito de transformação social.

Com vista a apoiar a criação e o desenvolvimento das incubadoras, em 1998, foi criado o Programa Nacional de Incubadoras de Cooperativas Populares (Proninc), que foi assumido formalmente pela Senaes em 2003. Nos últimos anos, o Proninc foi operacionalizado por meio de 
editais, que concederam recursos financeiros às incubadoras, e tem se destacado enquanto política pública no campo da economia solidária. A penúltima chamada MCTI/SECIS/MTE/SENAES/ $\mathrm{CNPq} \mathrm{n}^{\circ} 89 / 2013$ teve por objetivo selecionar propostas para apoio financeiro a projetos de pesquisa, desenvolvimento tecnológico e extensão que objetivam a incubação de empreendimentos econômicos solidários (EES).

Ao longo do tempo, as incubadoras ficaram reconhecidas como Incubadoras Tecnológicas de Economia Solidária (Ites), passaram a incorporar diversas atividades no processo de incubação e se aproximaram mais da concepção de assessoria contínua, principalmente diante dos empreendimentos já formados. Assim, ao assessorar um empreendimento, atua-se com a elaboração do planejamento e do plano de negócios, passa pela gestão da produção, pela produção de tecnologias sociais, pelas estratégias de comercialização, pelo suporte para acessar editais e políticas públicas, entre outras.

Algumas atividades estão para além da formação exclusiva de um empreendimento, preocupando-se, assim, com o desenvolvimento territorial e local, a difusão de conhecimentos, a produção de tecnologias e o fortalecimento e/ou a promoção de mobilização social. Dessa forma, em muitas incubadoras, a sistematização das metodologias de incubação no esquema tradicional de divisão entre pré-incubação, incubação e desincubação apresenta-se como um grande desafio.

Para Dubeux (2011), o trabalho desenvolvido pelas incubadoras brasileiras tem caráter político e pedagógico e se guia por um projeto, apesar de não ser consciente para todos os integrantes dela. O termo projeto é utilizado no sentido de idealizar um futuro, ou seja, promover uma ação que procura alterar o presente com promessas para o futuro.

O termo projeto político-pedagógico, que é normalmente aplicado em contextos escolares, pode ser também utilizado no contexto das incubadoras, pois o processo que elas realizam na formação e no acompanhamento dos grupos incubados é eminentemente político e pedagógico. É político no sentido de ter como objetivo promover uma transformação social por meio de produção de conhecimento útil às camadas populares e, consequentemente, úteis à sua inclusão e desenvolvimento social. É pedagógico porque visa à formação de cidadãos e atua no apoio ao processo de aprendizagem em torno da autogestão que impacta na dimensão coletiva dos EES e na transformação de certos aspectos da subjetividade de seus membros (DUBEUX, 2011).

As Ites representam ainda um estímulo à inovação, principalmente na perspectiva da tecnologia social, gerando novas ferramentas, tecnologias, metodologias, a partir do diálogo com os empreendimentos, e que podem ser difundidas e reaplicadas nos diferentes contextos de organizações coletivas e autogestionárias. A integração que as incubadoras promovem entre ensino, pesquisa e extensão fortalece a geração de conhecimento com a perspectiva da inovação social (OLIVEIRA et al., 2018).

Oliveira et al. (2018) apontam para uma nova perspectiva de geração de inovações e tecnologia, a qual não tem como finalidade estritamente o mercado ou a lógica financeira. Os conhecimentos produzidos no âmbito da incubação são, na sua maioria, de acesso amplo e irrestrito, e a elaboração dos processos, artefatos e ferramentas utilizam métodos participativos, que buscam um diálogo de saberes e partem das demandas e do contexto dos grupos produtivos (OLIVEIRA et al., 2018). 
Ainda sobre as ferramentas de gestão, elas apresentam inovações quanto ao entendimento e aplicação tradicional dos conceitos de planejamento, controle e organização do empreendimento, produzindo ferramentas de gestão que visam à viabilidade econômica dos empreendimentos, à garantia de maior autonomia de seus membros na gestão do coletivo e ao estabelecimento de relações democráticas. Além disso, há inovações que valorizam os aspectos substantivos dos empreendimentos, apoiando a relação com a comunidade e a cultura (OLIVEIRA et al., 2018).

\section{Gestão de Empreendimentos Econômicos Solidários}

Ao pensar a gestão dos Empreendimentos Econômicos Solidários (EES), há um grande desafio a ser superado, pois historicamente se reconhece a gestão (ou administração) como um conjunto de conhecimentos, técnicas e ferramentas voltado estritamente ao desenvolvimento empresarial. Assim, a concepção de gestão que vai operar nos arranjos produtivos é partidária de técnicas e procedimentos prescritivos, que capturam e desqualificam os saberes acumulados na atividade prática cotidiana das populações em favor de maior produtividade e lucro. A gestão é operada por pressões produtivas e financeiras que exigem instrumentos de avaliação e controle sobre os processos de trabalho. Em defesa da eficiência atribui-se a esses procedimentos uma roupagem de neutralidade, que os tornam supostamente necessários (AGUIAR, 2007; GAULEJAC, 2007).

Logo, esse suposto conhecimento que se pretende neutro e produzido por essa administração funcional, burocrática e gerencialista pouco contribui para o desenvolvimento de alternativas que visam construir outra forma de economia, como é o caso dos EES. Os estudos em gestão de EES têm apontado que devido às especificidades desses empreendimentos eles ainda carecem de uma abordagem teórica e metodológica adequada. Por outro lado, tem sido comum verificar a transferência de conhecimentos baseada em organizações empresariais sem a adaptação necessária e um baixo número de trabalhos que se apoiam em experiências práticas para trazer contribuições à ressignificação da gestão para esse campo (ANDION, 2005; CALBINO, 2013; CALBINO; PAULA, 2012; MEIRA, 2005; SILVA et al., 2005).

Os empreendimentos econômicos solidários, em teoria, caracterizam-se pela combinação da busca pela eficiência e viabilidade com o aprimoramento dos princípios cooperativos e democráticos; pela busca da sua autonomia de gestão com uma atitude de responsabilidade e de envolvimento social; e conjugam a obtenção de resultados econômicos com outros benefícios, como no plano da educação, da qualificação profissional, da cultura, entre outros (GAIGER, 2000).

Assim, além dos empreendimentos voltados para a geração de renda monetária propriamente dita, como as cooperativas, associações ou coletivos informais, também se unem aos EES outras organizações com outros objetivos que se integram a um projeto de desenvolvimento comunitário, como os clubes de trocas, grupos de consumo coletivos, organizações que trabalham com finanças solidárias (fundos rotativos, cooperativas de crédito, bancos populares), entre outros (SILVA, 2017).

Esses empreendimentos, por natureza, carregam consigo uma tensão entre a lógica mercantil e solidária que precisa ser gerida, pois, de um lado, a dimensão mercantil, o empreendimento, precisa se inserir no mercado para realizar atividades de compra e venda, gerar lucro, administrar 
os recursos escassos, lidar com relações de competição e fazer uso da racionalidade utilitária. De outro lado, a dimensão solidária, a racionalidade substantiva, está muito mais presente, pois o empreendimento desenvolve diversas relações de proximidade, preza pelas relações informais e busca pelos interesses sociais e coletivos acima dos interesses lucrativos individuais (SILVA JUNIOR, 2006).

A necessidade de regulação dessas tensões (mercantil e solidária) e a noção ampliada de economia fazem com que se reconheça que os resultados e o sentido de eficiência não sejam um dado puramente técnico e instrumental, seguindo uma racionalidade utilitária, mas sim uma dupla abordagem, contemplando também uma racionalidade substantiva. A eficiência organizacional na economia solidária passa a considerar outros aspectos, como a satisfação real das pessoas implicadas na organização, interna e externamente (FRANÇA FILHO, 2003), a reciprocidade, as relações de proximidade e o compromisso de transformação social (ANDION, 2005).

Nesse sentido, a sustentabilidade desses empreendimentos vai depender de uma convergência de fatores, como a intervenção pública, apoiada nos direitos sociais como princípios reguladores da economia, conquistas tecnológicas, política fiscal e normas jurídicas, como também a exigência de conhecimento por parte dos integrantes dos grupos e das condições necessárias para assumirem a condução de seu empreendimento.

Rutkowski (2008) salienta que há necessidade de um novo arcabouço teórico-metodológico a ser desenvolvido, uma vez que esses empreendimentos adotam formas alternativas de conhecimento baseadas, muitas vezes, em visões diferenciadas do mundo, que devem ser respeitadas e até mesmo reconhecidas como inovações. No campo do desenvolvimento tecnológico necessário à sustentabilidade desses empreendimentos não é diferente.

\section{Tecnologia Social, Economia Solidária e Gestão de Empreendimentos Econômicos Solidários}

Para Dagnino (2010a), a tecnologia pode ser um elemento essencial para a sustentabilidade da economia solidária, pois o problema não está apenas na organização do processo de trabalho, como supõe a maior parte dos autores que abordam essa questão a partir da perspectiva da economia solidária e da autogestão. Mas é da tecnologia em sentido amplo e, mais do que isso, da forma como se faz e se concebe a ciência. Assim,

\footnotetext{
Não é só a maneira como se organiza o trabalho (orgware), mas o substrato tecnológico (hardware e software) e o próprio substrato científico que de alguma maneira produzem a tecnologia que vai ser utilizada na empresa, o que precisa ser transformado. Não basta que o empreendimento seja de cooperados e nem que adote a autogestão. É necessário que disponha de TS (DAGNINO, 2004, p. 196).
}

Ele salienta que a tecnologia convencional é impregnada pela ideia da maximização do lucro privado e por uma reprodução da acumulação do capital que exige cada vez mais apropriação privada do conhecimento. Assim, a tecnologia que se propõe ser social não pode ser ingênua de adotar a transferência de conhecimento produzido pela comunidade de pesquisa, ainda que sensibilizada pelos atores sociais, sem que haja a participação efetiva na construção do conhecimento 
daqueles que a demandam, com a incorporação dos valores, interesses e saberes dos excluídos (DAGNINO, 2010b).

Frente a isso, a tecnologia social deve:

ser adaptada ao reduzido tamanho físico e financeiro; não-discriminatória; liberada da diferenciação - disfuncional, anacrônica e prejudicial nos ambientes autogestionários entre patrão e empregado; orientada para um mercado interno de massa; libertadora do potencial e da criatividade do produtor direto. Resumindo, deve ser capaz de viabilizar economicamente os empreendimentos autogestionários (DAGNINO, 2010b, p. 194).

A tecnologia a operar nos EES deve assim romper com os moldes da produção de tecnologia convencional e passar a operar em outra racionalidade, em que a técnica é submetida ao desenvolvimento social, o trabalho volta a ser elemento central e a manutenção de cada posto de trabalho tem prioridade em relação à lucratividade. A acumulação passa então a estar subordinada ao atendimento das necessidades definidas pelo coletivo de trabalhadores.

Ainda, para as tecnologias já produzidas, com incorporação de outros valores (empresariais), é possível que essas possam ser aproveitadas nos EES, mas após um processo de apropriação, o qual Dagnino (2004) conceitua como adequação sociotécnica, que se configura como:

(...) a participação democrática no processo de trabalho, o atendimento a requisitos relativos ao meio ambiente (mediante, por exemplo, o aumento da vida útil das máquinas e equipamentos), à saúde dos trabalhadores e dos consumidores e à sua capacitação autogestionária (DAGNINO, 2004, p. 53).

O conceito de adequação sociotécnica (AST) tem o objetivo de apresentar uma operacionalização da tecnologia social e prevê o processo de adequação do conhecimento científico e tecnológico aos interesses da transformação social. São processos reais de desconstrução e (re) projetamento tecnológico com participação de grupos sociais distintos daqueles que usualmente monopolizam a construção sociotécnica.

Assim, o desafio da autogestão se entende como a necessidade de desenvolvimento tecnológico que permita e estimule a gestão do empreendimento pelos trabalhadores, incorporando a participação e o controle destes na produção, sem serem subordinados aos peritos e técnicos, em que devem escolher entre eles ou votar nas alternativas apresentadas por eles. A subordinação rompe com a igualdade no empreendimento e tolhe a autonomia dos trabalhadores.

\section{Metodologia}

Esta pesquisa configurou-se como um estudo exploratório, que teve como objetivo traçar uma visão geral acerca dos conhecimentos produzidos pelas Ites no campo da administração. Como esse é um tema ainda pouco explorado, tornou-se difícil formular hipóteses precisas e operacionalizáveis. Desse modo, se buscou respostas para o problema de pesquisa a partir da visão e das experiências dos integrantes das incubadoras e dos materiais produzidos por eles. 
O presente artigo utilizou os dados quantitativos da pesquisa de Avaliação do Programa Nacional de Incubadoras de Cooperativa Populares (Proninc) realizada em 2016 e 2017 pelo Núcleo de Solidariedade Técnica da UFRJ (UNIVERSIDADE FEDERAL DO RIO DE JANEIRO, 2017). Já os dados qualitativos são oriundos de entrevistas semiestruturadas realizadas com os coordenadores, membros e ex-membros da Ites, selecionadas a partir dos dados quantitativos e de pesquisa documental com o intuito de buscar documentos que abordassem a metodologia de incubação e os resultados alcançados com os empreendimentos.

Em razão da extração de dados da pesquisa de avaliação do Proninc, o universo de estudo desta pesquisa se restringiu apenas às incubadoras participantes da pesquisa de avaliação, que totalizaram 64. Dentro desse universo, foram selecionadas apenas as incubadoras que realizaram incubação de pelo menos um empreendimento de catadores de materiais recicláveis. Essa escolha se deu pelo complexo contexto que envolve esses empreendimentos e as necessidades de desenvolvimento de estratégias em gestão para funcionarem.

Com base nesse resultado, delimitou-se ainda mais a amostra para análise aplicando os seguintes critérios que permitiram selecionar três incubadoras: ter mais de cinco anos de experiência com assessoria a empreendimentos de catadores; ter desenvolvido alguma tecnologia social com os catadores; maior número de empreendimentos incubados nos anos de 2014-2016.

A escolha desses critérios se deu devido à complexidade da organização de catadores, uma vez que exige a atuação do poder público e de políticas públicas adequadas, como também o diálogo com diversos atores, seja do movimento social, seja com as empresas privadas e com a população. Diante disso, um tempo muito curto de experiência poderia não ser suficiente para apresentar resultados e reflexões sobre a prática, como também o número de empreendimentos assessorados pode sinalizar maior maturidade nas práticas de incubação à organização de catadores.

Por fim, entendendo a tecnologia social (TS) como a tecnologia necessária à viabilização da autogestão, ou seja, uma tecnologia que é não discriminatória, liberada da diferenciação entre patrão e empregado, é libertadora do potencial e da criatividade do produtor direto e prevê o processo de adequação do conhecimento científico e tecnológico aos interesses da transformação social (DAGNINO, 2010b). Esse critério se justificou, pois o desenvolvimento de TS no âmbito de um EES irá gerar contribuições para a organização do processo de trabalho, e consequentemente, para a gestão do empreendimento.

As incubadoras entrevistadas foram: Incubadora de Cooperativas Populares da Universidade Estadual Paulista do Campus Assis (Unesp-Assis), Incubadora Social da Universidade Federal de Goiás (UFG) e a Incubadora do Núcleo Alternativas de Produção da Universidade Federal de Minas Gerais (UFMG). As entrevistas ocorreram na sede das incubadoras e foram realizadas entre novembro de 2017 e fevereiro de 2018.

O roteiro utilizado dividiu-se em duas partes, sendo que a primeira parte tinha como objetivo caracterizar a incubadora de forma geral, desde o momento da sua formação, os integrantes que fazem parte, a organização interna para o trabalho e as concepções dos membros sobre a gestão de empreendimentos solidários. A segunda parte buscou entender como se estruturava o 
processo de incubação e como ele era concebido, como os problemas do empreendimento eram incorporados na metodologia de incubação/assessoria e de que forma os aspectos da gestão eram contemplados na metodologia de incubação/assessoria.

Após a análise das entrevistas e dos documentos coletados iniciou-se a organização desses conteúdos de modo a estabelecer unidades de análise. Identificou-se, assim, um feixe de relações temáticas nas falas dos entrevistados, que deram origem às categorias que foram analisadas.

É importante destacar que esta pesquisa optou por restringir o universo da pesquisa apenas à entrevista com as incubadoras, ou seja, não abordar a perspectiva dos empreendimentos incubados, pois o acesso aos membros e às informações dos empreendimentos demandaria tempo, além do disponível pela pesquisadora, para estabelecer vínculo e abertura adequada para obter informações qualificadas sobre o impacto da incubação na gestão do empreendimento.

\section{Resultado}

\section{Caracterização das Incubadoras Pesquisadas}

A Incubadora Social da Universidade Federal de Goiânia iniciou suas atividades em 2007 e 2008, mobilizadas pelo Programa Goiânia de Coleta Seletiva. A partir de um levantamento sobre as dificuldades de organização dos catadores e sobre as condições de trabalho inadequadas e insalubres, elaborou-se um projeto de implantação da incubadora social que previa assessorar grupos de catadores da região metropolitana de Goiânia.

Entre 2014 e 2016, foram registrados 23 empreendimentos assessorados pela incubadora, sendo 1 formalizado como associação, 18 como cooperativas e 4 não foram registrados, mantendo-se como grupos informais. Desses empreendimentos nenhum foi desincubado, e a incubadora não estipula um tempo ideal ou exato para um empreendimento ser incubado, pois isso varia de acordo com o contexto.

Baseada nos preceitos de Paulo Freire e da Educação Popular, a incubadora tece sua metodologia de incubação utilizando alguns métodos e processos centrados na oralidade e exploração de palavras e imagens construídas a partir dos saberes referentes ao mundo real e concreto dos integrantes do grupo para desenvolver reflexões e ações nas seguintes áreas de incubação que compõem a organização socioprodutiva: ambiental, cadastramento, contabilidade, gestão social, economia, jurídica, comunicação e material pedagógico.

Além disso, dois métodos foram destaques para compor a metodologia de incubação: a Oficina Prática de Autogestão (OPA) e o "Combinou, tá combinado". A OPA consiste em uma oficina de formação como também numa prática de autogestão, em que os temas trabalhados são pré-agendados e seguem os eixos temáticos propostos pela incubadora. Eles são trabalhados inicialmente por meio de apresentação de situações problemas, identificadas e vivenciadas pelos próprios membros do empreendimento ou pela apresentação de temas e dinâmicas relevantes ao processo de trabalho na cooperativa. Busca-se realizar essas oficinas em roda e utilizando técnicas que promovam a exposição de ideias, como a tempestade de ideias, recursos audiovisuais e dinâmicas. 
O resultado da discussão desenvolvida no grupo é o "combinado" que leva à produção de uma imagem síntese e de sentido comum a todos os membros do grupo, obtida por meio da "combinação", ou seja, pelo voto dos participantes. Essa imagem é transportada para dois artefatos: encarte em fichário individual e cartaz a ser afixado nas dependências do empreendimento com o objetivo de reforçar a cultura organizacional de ambiente autogestionário em construção.

A incubadora também prevê um "período de maturação", onde são vivenciadas as experiências decorrentes da "combinação" e, assim, são pautados novos temas a proporcionar a crítica e avaliação da experiência pelo próprio grupo. Esse período ocorre entre a realização das oficinas.

O método "Combinou, tá combinado" refere-se à construção de normas de constituição e funcionamento (estatuto e regimentos) do empreendimento, passando pela formação e capacitação dos grupos em todas as etapas do processo de incubação a partir da pré-incubação. Ele permite, assim, a elaboração de um material pedagógico por meio de conclusões sobre a própria realidade, seja relativa ao trabalho e renda, como também social, política e econômica e seus conflitos, na qual estão inseridos.

Dentre as inovações produzidas com os grupos, destacam-se a construção coletiva de planilhas e controles financeiros com a prática da contabilidade pedagógica e a implantação de uma incubadora pública local, responsável pela assessoria aos empreendimentos dentro da estrutura da prefeitura municipal de Goiânia.

A segunda incubadora selecionada foi a incubadora do Núcleo Alternativas de Produção (NAP) da Universidade Federal de Minas Gerais, que nasceu da intenção de construir conhecimentos em engenharia que pudessem dar suporte aos processos de organização e produção das cooperativas e associações de catadores. Sua atuação começou no início dos anos 2000, com atividades de pesquisa e extensão com e para o movimento de economia solidária, e se formalizou em 2008 dentro do Departamento de Engenharia de Produção da UFMG.

Entre 2014 e 2016, a incubadora registrou assessoria a um total de 12 empreendimentos, sendo 5 formalizados como associação e 7 formalizados como cooperativa. A maior parte dos empreendimentos assessorados pelo núcleo possui um tempo de acompanhamento de até 1 ano.

Ao longo do processo inicial de assessoria a esses grupos, os membros do núcleo constataram que as especificações técnicas de um projeto ou artefato produzido e as formas de organização do trabalho possuem forte relação de interdependência, por exemplo, a substituição do carrinho de coleta individual por um caminhão não era apenas questão de eficiência, a proposta gerava um problema para os catadores, pois estes viam no carrinho um símbolo que os representava. Ou então, a implementação de uma esteira, onde a coleta e o pagamento eram feitos de forma individual, gerava novas questões de como organizar e controlar a participação de cada membro na esteira, como o horário de trabalho, a intensidade, a dedicação, o pagamento, etc. que eram problemas que apenas a elaboração técnica de artefatos não dava conta.

Assim, a inadequação inicial dos projetos à realidade dos trabalhadores fez com que os membros do grupo fossem obrigados a pensar metodologias de elaboração de projetos em engenharia mais participativos e que pudessem auxiliar no desenvolvimento da autonomia e da auto- 
gestão. O núcleo trabalha com demandas técnicas de engenharia e de melhorias organizacionais em galpões de cooperativas de catadores de materiais recicláveis.

A metodologia utilizada pelo grupo fundamenta-se em metodologias participativas, como a pesquisa-ação, e também na análise ergonômica do trabalho. Ela não segue as etapas ou fases da incubação tradicional (pré-incubação, incubação, pós-incubação) e funciona mais como assessoria contínua e pontual em torno de necessidades identificadas e/ou apontadas pelos cooperados. Normalmente, iniciam com um diagnóstico participativo, desenvolvendo modelos em escala dos principais equipamentos, que são feitos em papelão, Lego e em peças de impressão 3D, para facilitar a definição coletiva de layout dos galpões. Esses instrumentos, que permitem uma interface entre técnicos e beneficiários, são denominados pelo grupo como objetos intermediários. A partir desses objetos, os técnicos buscam simular a realidade para a construção coletiva de uma solução e para compreender as necessidades dos catadores e do processo produtivo. Além deles, também se utilizam entrevistas coletivas semiestruturadas, observação participante e análise do trabalho.

Nos últimos anos, está em fase de desenvolvimento outro método de abordagem, que eles chamam de "incubação ao inverso". Nessa perspectiva, já não há necessidade de diagnóstico, mas de uma demanda concreta e clara dos empreendimentos. Diante disso, propõe-se uma imersão no campo, utilizando, dentre elas, uma técnica inspirada na Instrução ao Sósia (ALMEIDA; LIMA, 2017), em que o técnico se insere no processo produtivo dos catadores pedindo instruções aos catadores sobre a rotina de trabalho que deve exercer. Essa estratégia é utilizada com o intuito de entender a realidade do trabalho dos catadores e propor questionamentos, a fim de gerar novas formas de organização da produção.

Por fim, a Incubadora Alter-Nativas não baseia suas ações no espaço da sala de aula, em atividades exclusivas de formação teórica ou ao espaço relativamente protegido de uma "incubadora”. Aposta, para que haja capacitação efetiva, numa exposição direta ao crivo da prática, pois somente assim se pode educar o educador. A incubação acontece, portanto, nos próprios locais de trabalho, e em casos eventuais realizam-se oficinas para socialização de experiências em espaços da universidade.

Aúltima incubadora selecionada foi a Incubadora de Cooperativas Populares da Universidade Estadual Paulista (Incop da Unesp) situada no campus de Assis, interior de São Paulo. Ela iniciou suas atividades em 2001, mas formalizou-se como incubadora apenas em 2006. As atividades iniciaram com a atuação de dois professores (hoje coordenadores) com trabalhadores desempregados da cidade na perspectiva de discutir a situação que viviam (do desemprego) e mais posteriormente desenvolver atividades que levassem a alternativas de geração de trabalho e renda.

O primeiro grupo incubado se formou, inicialmente, coletando de forma individual e comercializando em conjunto e contou com a participação de outros trabalhadores que não eram catadores, mas estavam desempregados, que atuavam na organização do material. Em meados de 2003, o grupo, com o apoio do projeto universitário e de outras organizações, criou a Cooperativa de Catadores de Materiais Recicláveis de Assis (COOCASSIS) (CARVALHO et al., 2016b). A experiência da cooperativa tornou-se referência na região e foi demandada por outros munícipios vizinhos que passaram a solicitar a assessoria da incubadora na formação de outros empreendimentos com o objetivo de implementar a coleta seletiva com inclusão dos catadores. 
Desde o início da sua atuação, a Incop possui foco principal na incubação de empreendimentos de catadores. Hoje ela se encontra vinculada ao Departamento de Psicologia da Faculdade de Ciência e Letras da Unesp - Assis e colabora com a formação de psicólogos na ênfase de trabalho, subjetividade e administração do social.

Quanto aos empreendimentos de catadores incubados foram num total de nove durante os anos de 2014 e 2016, dos quais cinco formalizados como associação e quatro como cooperativas.

O tempo de incubação dos empreendimentos varia de 2 a mais de 8 anos e não há até hoje nenhum empreendimento "desincubado". A incubadora não estipula prazo mínimo nem máximo de incubação. Os coordenadores partem do princípio de que não há necessidade de desincubar, pois eles veem que os empreendimentos que passaram dois anos sendo incubados e depois foram desincubados não sobreviveram. Eles acreditam que a assessoria deve acontecer por tempo indeterminado até quando eles quiserem e alegam que cada empreendimento tem dinâmicas distintas ao longo do tempo, com fases diferentes e pessoas diferentes.

A incubadora se apoia em referenciais teórico-metodológicos críticos que consideram o homem como sujeito ativo, histórico e social. Os fundamentos pedagógicos que compõem a metodologia de incubação são: metodologias participativas, teorias críticas, educação popular, economia solidária e cooperativismo popular.

A intervenção da incubadora se pautou inicialmente nas demandas que emergiam do cotidiano dos grupos, buscando construir estratégias que levassem os grupos a se desnaturalizarem e entenderem a realidade como uma construção social histórica. Essa intervenção se dava em encontros sistemáticos, reuniões e visitas semanais, e, dependendo do grupo, as reuniões ocorriam com todo o empreendimento ao mesmo tempo ou com grupos separados, em um momento com o conselho fiscal, em outro com o conselho de administração ou ainda com o "grupão".

Em dado momento, a incubadora percebeu que essa prática não ajudava a pensar o empreendimento a longo prazo, apenas a "apagar incêndios". Visando remediar isso com planos sustentáveis para os empreendimentos, criou-se a ferramenta que hoje eles nomeiam como "Roteiro de Identificação da Situação Atual das Associações e Cooperativas de Catadores e Catadoras (RISAAC)".

Segundo os dados da entrevista, a ferramenta foi, durante três anos, com a participação de representantes dos empreendimentos da região do Oeste Paulista, cujos objetivos são: a) identificar a situação atual da associação ou cooperativa; b) buscar alternativas para a superação dos desafios cotidianos; c) construir propostas para o desenvolvimento sustentável do empreendimento; d) fazer um plano de trabalho que oriente as ações do grupo; e) contribuir para o fortalecimento do grupo.

Com o processo foi possível chegar a três grandes dimensões que são importantes para o desenvolvimento de um empreendimento de catadores, conforme a Tabela 1. Essa separação em dimensões é utilizada como um recurso didático, porque na prática elas se integram. 
Tabela 1. Estrutura e funcionamento do Roteiro de Identificação da Situação Atual das Associações e Cooperativas de Catadores e Catadoras (RISAAC).

\begin{tabular}{|c|c|c|}
\hline Eixo temático & Tema & Subtema \\
\hline \multirow{2}{*}{$\begin{array}{c}\text { I. Gestão do Processo } \\
\text { Produtivo }\end{array}$} & $\begin{array}{l}\text { A. Comercialização e } \\
\text { Renda }\end{array}$ & $\begin{array}{l}\text { 1. Origem dos materiais processados no empreendimento } \\
\text { 2. Quantidade de material coletado e comercializado } \\
\text { 3. Como e com quem comercializa } \\
\text { 4. Renda de cooperadas e cooperados }\end{array}$ \\
\hline & B. Processo Produtivo & $\begin{array}{l}\text { 1. Espaço físico utilizado } \\
\text { 2. Veículos existentes } \\
\text { 3. Equipamentos existentes } \\
\text { 4. Avaliação do processo produtivo }\end{array}$ \\
\hline \multirow{2}{*}{$\begin{array}{c}\text { II. Gestão } \\
\text { Administrativa e } \\
\text { Democrática }\end{array}$} & $\begin{array}{c}\text { A. Gestão } \\
\text { Administrativa e } \\
\text { Legalidade }\end{array}$ & $\begin{array}{l}\text { 1. Formalização e manutenção da legalidade e do } \\
\text { empreendimento } \\
\text { 2. Registro administrativo e contábil } \\
\text { 3. Pagamento da Previdência Social } \\
\text { 4. Fundos e/ou benefícios mantidos pelo empreendimento }\end{array}$ \\
\hline & $\begin{array}{c}\text { B. Gestão } \\
\text { Democrática e } \\
\text { Participativa }\end{array}$ & $\begin{array}{l}\text { 1. Gestão democrática } \\
\text { 2. Saúde no trabalho } \\
\text { 3. Formação/capacitação das associadas e associados } \\
\text { 4. Relação entre membros do empreendimento }\end{array}$ \\
\hline \multirow[t]{2}{*}{ III. Relação Externa } & $\begin{array}{l}\text { A. Comunidade Local } \\
\text { e Poder Público }\end{array}$ & $\begin{array}{l}\text { 1. Autonomia na gestão } \\
\text { 2. Apoios e parcerias } \\
\text { 3. Acesso a políticas públicas } \\
\text { 4. Comunicação com o poder público (Prefeitura, Câmara } \\
\text { 5unicipal) } \\
\text { 5. Comunicação com a comunidade } \\
\text { 6. Interesse pela comunidade } \\
\text { 7. Trabalho educativo com a população }\end{array}$ \\
\hline & $\begin{array}{l}\text { B. Movimento dos } \\
\text { Catadores e Economia } \\
\text { Solidária }\end{array}$ & $\begin{array}{l}\text { 1. Participação no Comitê Oeste Paulista e em ações de } \\
\text { cooperação com outros grupos } \\
\text { 2. Comercialização em rede } \\
\text { 3. Envolvimento com a Economia Solidária }\end{array}$ \\
\hline
\end{tabular}

Fonte: Carvalho et al. (2016c, p. 38).

Assim, em gestão do processo produtivo, discutem-se e avaliam-se as condições e ações existentes referentes ao processo de organização do trabalho, abordando diretamente a comercialização e renda e os meios de produção. Em gestão administrativa e democrática trata-se das ações e das condições da gestão do grupo, como a formalização, transparência e participação das associadas e associados na organização e na realização do trabalho, sendo dividido entre gestão administrativa e legalidade e gestão democrática e participativa. Já em relação externa abordam-se as ações e condições de relacionamento com outros grupos de catadores e catadoras, com entidades, órgãos públicos e com a sociedade civil, dividindo-se em comunidade local e poder público e movimento dos catadores e economia solidária.

Um dos impactos relatados com o instrumento foi: maior percepção sobre a situação do empreendimento, conquista de maior autonomia dos cooperados diante do Conselho de Administração, fortalecimento da relação de parceria e confiança com a incubadora. 


\section{Análises das Contribuições das Incubadoras para a Gestão}

Em busca de respostas para a questão proposta no início deste trabalho, o presente artigo analisa as experiências das incubadoras tecnológicas de economia solidária para verificar que conhecimentos e tecnologias em gestão estão sendo produzidos para dar conta da realidade e especificidade dos EES. A partir da experiência das incubadoras descritas acima pode-se afirmar que o processo de incubação e assessoria é um processo contínuo de formação (dos técnicos e dos trabalhadores) e produção tecnológica para uma organização solidária.

Torna-se importante reconhecer que as pessoas que participam do empreendimento costumam trazer consigo experiências de trabalho do modo de produção capitalista, no qual sempre tem alguém que vai dizer para o outro o que ele deve ou não fazer. Então, como lidar com isso na organização de um empreendimento autogestionado? De acordo com um dos coordenadores da Incop/Assis, esse é um processo complicado, porque tem que acontecer para os dois lados, tanto para quem se coloca numa posição de gestão dentro do empreendimento, quanto para os que se colocam numa posição de submissão e não se deixam questionar, cobrar e/ou discordar. Assim, é preciso quebrar a dicotomia entre patrão/gestor e empregado/trabalhador, uma vez que todos são responsáveis pela gestão.

Verificou-se que as incubadoras têm promovido intervenções e ações nesse sentido, seja com cursos e formações sobre cooperativismo e economia solidária, conforme relatado pela incubadora social da UFG e pela Incop/Assis, seja com metodologias e técnicas que promovam e exercitem valores e hábitos democráticos, com o desenvolvimento das oficinas práticas de autogestão pela incubadora social da UFG, ou ainda com o desenvolvimento de projetos técnicos de engenharia para o processo produtivo que buscam contemplar a autogestão, conforme a incubadora do NAP.

Nas metodologias utilizadas pelas incubadoras percebe-se a existência de espaços de diálogos com os grupos, seja com todos os cooperados ou membros, seja especificamente com o conselho administrativo e/ou conselho fiscal. Na Incop/Assis esses espaços constituíram-se em momentos de problematização sobre a realidade em busca de novos modos de atuação, com momentos de planejamento e formação. Já na incubadora social da UFG, esses espaços se caracterizaram principalmente com as OPAs. Assim, as incubadoras buscaram promover a participação criando os espaços e a prática de diálogo dentro dos empreendimentos. Já a incubadora do NAP utilizou objetos e processos que auxiliaram na intermediação da negociação entre trabalhadores e técnicos sobre as determinações técnicas dos instrumentos de trabalho das cooperativas, criando assim um espaço de discussão e autogestão sobre a técnica, além de processos de imersão e questionamentos sobre (e nos) cotidianos de trabalho.

Verifica-se ainda que há dois grandes ganhos advindos dos espaços de diálogo criados pelas incubadoras, um é quanto aos processos de comunicação, tanto no estímulo à prestação de contas como no incentivo à comunicação sobre os problemas enfrentados no cotidiano. $\mathrm{O}$ outro ganho é quanto à possibilidade de criar novas técnicas e metodologias de gestão adequadas às necessidades de cada empreendimento.

Os EES, por serem pautados pelos princípios da autonomia e da liberdade e por conseguirem concretizar espaços de participação, acabam por decidir sobre os modos de gestão que melhor 
se adequam às suas necessidades e características, sendo mais difícil estabelecer padrões e prescrições universais para o desenvolvimento dos empreendimentos (AGUIAR, 2007; CALBINO, 2013). Assim foi possível identificar, no relato das incubadoras, casos em que os empreendimentos conseguiram propor novos modos de controle, inclusão e organização da produção, muitas vezes permeados de uma racionalidade substantiva.

As novas técnicas, métodos e processos construídos no âmbito da incubação dialogam diretamente com os princípios da tecnologia social propostos por Dagnino (2010b), pois a criação de tecnologias sociais precisou ser discutida nos espaços de diálogo dos empreendimentos e operaram na produção de valores e lógicas vinculados à promoção da solidariedade.

Assim, a não padronização de métodos e processos junto com a racionalidade substantiva dos modos de organização desses empreendimentos se apresentaram como um desafio complexo a ser entendido e incorporado nas soluções técnicas para o NAP. O professor coordenador do núcleo, em entrevista, afirma que as noções de solidariedade são distintas em cada associação e que elas se reproduzem em cada organização nas condições que são possíveis. Ao longo do processo de acompanhamento aos empreendimentos percebeu-se que, para que houvesse um ganho ou aumento da solidariedade, era necessário mudar as condições do trabalho, e não necessariamente esperar que a solidariedade dos grupos mudasse a forma de trabalho.

Com a instalação de uma esteira em uma cooperativa, houve diversas transformações na organização do trabalho dos catadores que precisaram ser trabalhadas pelo NAP. Uma das percepções destacadas pelo grupo é que o controle da produção nas cooperativas de catadores ganha conotação de regulação e envolve um processo de negociação e confiança em que os critérios deixam de ser apenas objetivos e econômicos e passam também a ser subjetivos, pois os critérios para controle das paradas da esteira passam por diversos motivos, como paradas para ir ao banheiro, para dar vazão ao acúmulo de material de determinada cooperada, para fumar, ou ainda porque tá fazendo "corpo mole". O controle do trabalho passa por um controle do grupo sobre poder acreditar no cansaço (ou não) do outro.

Assim, a introdução de uma esteira de trabalho, ao mesmo tempo em que pode trazer ganhos para a capacidade de triagem do empreendimento, também pode gerar tensões e conflitos no relacionamento entre os trabalhadores, os quais precisam ser pensados juntos com os técnicos e nos projetos de engenharia.

A mudança na organização do trabalho dos catadores também foi afetada pela tensão entre as racionalidades, substantiva e utilitária. Um dos casos relatados pela incubadora do NAP que ilustra essa visão é que no início dos trabalhos do núcleo, de acompanhamento aos catadores, em dada cooperativa estava sendo desenvolvido um modelo de logística de coleta para otimizar e racionalizar as rotas de coleta do caminhão dela. No entanto, o modelo não foi utilizado pelos catadores, pois não correspondia às razões e aos critérios para definição da rota utilizados pelos catadores. Para eles, era mais importante atender uma mobilização espontânea da população, que tinha um vínculo e compromisso com eles, mesmo que fosse preciso deslocar o caminhão para pegar uma pequena quantidade de material, do que se negar. Percebeu-se então que os critérios utilizados pela incubadora para definir uma rota eram puramente em razão da rentabilidade econômica de eficiência, sem pensar nos aspectos substantivos. 
As considerações sobre essa outra racionalidade e as noções de solidariedade não entravam no problema e na solução técnica, e assim as ferramentas propostas acabavam inoperantes e sem resolver o problema das cooperativas. Dessa forma, é possível afirmar que não são apenas as assessorias que criam novos conhecimentos ou uma visão crítica da administração. A razão substantiva está presente também nos coletivos de trabalhadores sem patrões que apresentam elementos não esperados pelas assessorias. Reconhecer essa outra dimensão para as elaborações técnicas, incorporando e criando uma outra noção de eficiência, ainda é um processo em construção pela incubadora do NAP.

Com a sistematização das experiências é possível destacar ainda uma inovação quanto às áreas funcionais da administração. Tradicionalmente concebe-se a divisão dos processos administrativos em: marketing, recursos humanos, logística, financeiro. No entanto, com base na elaboração do RISAAC, nas organizações de catadores, as áreas funcionais tendem a se deslocar para: gestão do processo produtivo, gestão administrativa e democrática e relações externas. Essas áreas funcionais abrangem não apenas a gestão interna do empreendimento, como a comercialização e gestão dos processos, mas concebe uma dimensão política e local do empreendimento como parte da gestão dele, considerando a relação com o entorno, com agentes públicos, o acesso a políticas públicas e ao movimento nacional da categoria. Dessa forma, as áreas funcionais da administração, pretensamente universais e neutras, perdem aderência ao se analisar a realidade dos empreendimentos de catadores, que demandam outras áreas e funcionalidades.

É importante destacar o vínculo de confiança gerado entre empreendimentos e incubadoras para a realização da assessoria. Fato que também se relaciona com o tempo de atuação da incubadora, todas as incubadoras tinham mais de cinco anos de atuação. Elas relataram que o vínculo de confiança construído com os grupos de catadores foi um elemento preponderante para o desenvolvimento da assessoria, das ferramentas e das resoluções de conflitos ou impasses. Diferentemente de uma consultoria, em que se preza pelos aspectos técnicos ou a capacidade de resultados econômicos do processo, as incubadoras são escolhidas pelos empreendimentos por aspectos substantivos da relação.

Por fim, a questão do tempo se revelou de extrema importância na organização dos empreendimentos solidários de catadores e dos seus processos democráticos. Por um lado, identifica-se que a estratégia em comum entre as três incubadoras refere-se ao fato de todas as incubadoras analisadas terem em média dez anos de atuação com o tema ou possuírem pesquisadores e extensionistas na equipe com tempo maior de dedicação à área, o que possibilitou o desenvolvimento do vínculo atual com os grupos incubados. Mostraram ainda ser elementos importantes para gerar contribuições relevantes para a gestão desses empreendimentos.

Mesmo considerando os avanços verificados na assessoria com as incubadoras, percebe-se a necessidade de continuidade dessa atuação, pois a organização de catadores em cooperativas, assim como os programas de coleta seletiva, ainda é incipiente e carece de formação continuada, acompanhamento e orientações técnicas para organização, planejamento e execução, por se tratarem de fenômenos que requerem tempo para amadurecimento das práticas, criação e fixação de conhecimentos específicos, os quais, normalmente, não são tratados de forma adequada pelos agentes de fomento, tanto públicos como privados. 


\section{Considerações Finais}

Diante de uma administração funcional, burocrática e gerencialista, pouco se pode aproveitar para o desenvolvimento de alternativas que visam construir uma sociedade pautada por novas formas de sociabilidade e reciprocidade. Em busca de novos conhecimentos, as Ites se constituíram, ao longo dos anos, como espaços profícuos para o desenvolvimento de tecnologias sociais que contribuem para a sustentabilidade e viabilidade de outra economia.

A partir das experiências das três incubadoras é possível afirmar que já há processos educativos em curso que conseguem propor novas formas democráticas de gestão. Seja com o desenvolvimento de espaços de diálogo na organização do empreendimento, seja com o reconhecimento e incorporação de diversas racionalidades na produção de técnicas, métodos, processos e/ ou artefatos, seja com a criação de novas áreas funcionais para a gestão do empreendimento, seja com o reconhecimento de aspectos subjetivos que irão impactar na formação e gestão do empreendimento, como a confiança e o tempo.

O presente trabalho apresenta como limitação metodológica a escolha por entrevistar apenas os membros das incubadoras, essa limitação acarretou em análise parcial da realidade, sendo necessário, para aprofundamento, abordar os resultados da prática de incubação pela percepção dos empreendimentos, levantando quais os resultados efetivos dos procedimentos criados e que novos modos de gestão foram desenvolvidos a partir das assessorias.

Por fim, identificou-se também que a criação de uma gestão que possa promover práticas econômicas alternativas passa pelo reconhecimento e valorização das diversas racionalidades que constituem a organização. Para isso é preciso haver espaços de diálogos e trocas horizontais entre quem "presta assessoria" e "quem é assessorado", para que não haja a subordinação da racionalidade de quem presta assessoria sobre os grupos assessorados, e sim que haja um processo educativo e de troca entre ambos os lados.

\section{Referências}

AGUIAR, K. Economia dos setores populares: modos de gestão e estratégias de formação. In: KRAYCHETE, G.; AGUIAR, K. Economia dos setores populares: sustentabilidade e estratégias de formação. São Leopoldo: Oikos, 2007. p. 106-121.

ALMEIDA, A. P. de C.; LIMA, M. E. A. A instrução ao sósia no contexto da pesquisa: diferentes modos de apropriação do instrumento. Horizontes, v. 35, n. 3, p. 58-70, 29 dez. 2017. DOI: http://dx.doi. org/10.24933/horizontes.v35i3.521.

ANDION, C. A gestão no campo da economia solidária: particularidades e desafios. Revista de Administração Contemporânea, v. 9, n. 1, p. 79-101, 2005.

CALBINO, D. Em busca de contribuições para a gestão na economia solidária: um estudo a partir da literatura e do caso Cecosesola. 2013. 395 f. Tese (Doutorado em Administração) - Faculdade de Ciências Econômicas, Universidade Federal de Minas Gerais, Belo Horizonte.

CALBINO, D.; PAULA, A. P. P. A Gestão na economia solidária: um estudo nas incubadoras de empreendimentos solidários. Gerais: Revista Interinstitucional de Psicologia, v. 5, n. 1, p. 108-126, 2012. 
CARVALHO, A. M. R. de; LADEIA, C. R.; SANTOS, F. L. dos; OLIVEIRA, P. M. B. Metodologias participativas: estratégias para o fortalecimento de grupos populares. In: CARVALHO, A. M. R. de; LADEIA, C. R. S. (Org.). Metodologia de incubação e de diagnostico participativo: estratégia de trabalho com grupos populares. São Paulo: Cultura Acadêmica e Canal 6, 2016a. p. 91-120.

CARVALHO, A. M. R. de; LADEIA, C. R.; FELÍCIO, R. G. Incubadora de cooperativas populares da Unesp Assis: percurso de uma experiência em extensão universitária. In: CARVALHO, A. M. R. de; LADEIA, C. R. Metodologia de incubação e de diagnostico participativo: estratégia de trabalho com grupos populares. São Paulo: Cultura Acadêmica, 2016b. p. 27-48.

CARVAlHO, A. M. R. de; ZÓIA, A. B.; VAlÊNCIO, A.; LADEIA, C. R.; CALÇADO, D. R. (Org.). RISAAC - Roteiro de Identificação da Situação Atual de Associações/Cooperativas de Catadoras e Catadores de materiais recicláveis. Assis: Unesp - Campus Assis, 2016c.

CORRAGIO, J. L. ¿Qué es lo económico y que es otra política? In: LIANZA, S.; HENRIQUES, F. C. (Org.). A economia solidária na América Latina: realidades nacionais e políticas públicas. Rio de Janeiro: Pró Reitoria de Extensão UFRJ, 2012. p. 21-46.

DAGNINO, R. A Tecnologia social e seus desafios. In: LASSANCE JUNIOR, A. E. et al. Tecnologia social: uma estratégia para o desenvolvimento. Rio de Janeiro: Fundação Banco do Brasil, 2004. p. 187-210.

DAGNINO, R. Apresentação. In: DAGNINO, R. (Org.). Tecnologia social: ferramenta para construir outra sociedade. Campinas: Komedi, 2010a. p. 7-22.

DAGNINO, R. Em direção a uma teoria crítica da tecnologia. In: DAGNINO, R. (Org.). Tecnologia social: ferramenta para construir outra sociedade. Campinas: Komedi, 2010b. p. 113-152.

DUBEUX, A. Incubação de grupos de catadores de resíduos sólidos, compartilhando conhecimentos e construindo inovação social. In: ZANIN, M.; GUTIERREZ, R. (Org.). Cooperativas de catadores. São Carlos: Claraluz, 2011.

FRANÇA FILHO, G. C. A temática da economia solidária e suas implicações originais para o campo dos estudos organizacionais. Revista de Administração Pública, v. 37, n. 1, p. 11-31, jan. 2003.

FRANÇA FILHO, G. C. Teoria e prática em economia solidária: problemática, desafios e vocação. Civitas, v. 7, n. 1, p. 155-174, jan.-jun. 2007.

GAIGER, L. I. Sentidos e possibilidades da economia solidária hoje. In: KRAYCHETE, G. et al. Economia dos setores populares: entre a realidade e a utopia. Petrópolis: Vozes, 2000. p. 167-198.

GAULEJAC, V. A. Gestão como doença social: ideologia, poder gerencialista e fragmentação social. Aparecida: Idéias \& Letras, 2007.

HENRIQUES, F. C. Empresas recuperadas por trabalhadores no Brasil e na Argentina. 2013. $334 \mathrm{f}$. Tese (Doutorado em Planejamento Urbano e Regional) - Instituto de Pesquisa e Planejamento Urbano e Regional (IPPUR/UFRJ), Universidade Federal do Rio de Janeiro, Rio de Janeiro.

HENRIQUES, F. C. O conceito de economia solidária. In: ADDOR, F.; HENRIQUE, F. C. Tecnologia, participação e território: reflexões a partir da prática extensionista. Rio de Janeiro: UFRJ, 2015. p. 23-46.

LEITE, M. de P. A economia solidária e o trabalho associativo: teorias e realidades. Revista Brasileira de Ciências Sociais, v. 69, n. 24, p. 31-51, fev. 2009.

MEIRA, L. A gestão de empreendimentos econômicos solidários: olhares das ITCPs USP, UFRJ e UNEB. 2005. 107 f. Dissertação (Mestrado em Administração) - Escola de Administração, Universidade Federal da Bahia, Salvador. 
OLIVEIRA, T. C. S. de; ADDOR, F.; MAIA, L. As incubadoras tecnológicas de economia solidária como espaço de desenvolvimento de tecnologias e inovações sociais. Revista Tecnologia e Sociedade, v. 14, n. 32, p. 38-59, maio 2018.

RUTKOWSKI, J. Sustentabilidade de empreendimentos econômicos: uma abordagem na engenharia de Produção. 2008. Tese (Doutorado em Engenharia de Produção) - Universidade Federal do Rio de Janeiro, Rio de Janeiro.

SILVA, M. R.; TEXEIRA, L. R.; VASCONCELOS, O. A. "O ensino de uma "outra gestão": o caso da Escola de Administração da Universidade Federal da Bahia". Trabalho apresentado nos anais do 29. ENANPAD, 2005, Brasília, DF.

SILVA JUNIOR, J. T. O desafio da gestão de empreendimentos da economia solidária: as tensões entre as dimensões mercantil e solidária na ASMOCONP/Banco Palmas - CE. Trabalho apresentado nos anais do 30. EnANPAD, 2006, Salvador.

SILVA, S. P. A Organização coletiva de catadores de material reciclável no Brasil: dilemas e potencialidades sob a ótica da economia solidária. Rio de Janeiro: Instituto de Pesquisa Econômica, 2017.

SINGER, P. Introdução a economia solidária. São Paulo: Fundação Perseu Abramo, 2002. 127 p.

UNIVERSIDADE FEDERAL DO RIO DE JANEIRO. SOLTEC - Núcleo de Solidariedade Técnica. Avaliação do Proninc - avaliação participativa, qualitativa e quantitativa das ações do Programa Nacional de Incubadoras de Cooperativas Populares - relatório final, 2017. Rio de Janeiro, 2017. Disponível em: https://nides.ufrj.br/index.php/projetos-soltec/proninc. Acesso em: 30 jun. 2019. 
